\title{
Retaining educational fundraisers: Reducing turnover by investing in human capital management
}

\author{
Received (in revised form): 20th May 2010
}

\section{Christy Thomas}

is the associate director for foundation relations for the College of Arts \& Sciences (CAS) at the University of Washington. She directs (including identification, cultivation and management) the solicitation process for foundation gifts in support of the CAS. In this role, she works proactively with academic leaders to develop fundraising strategies that support arts, humanities, social and natural sciences and interdisciplinary projects. Previously, she worked for Carnegie Mellon University as Director of the Parents Fundraising Program \& major gift officer. In this role, she was part of the university's first $\$ 1$ billion campaign and also completed a Masters in Public Management with a Human Capital Management concentration from the John H. Heinz College at Carnegie Mellon.

ABSTRACT This article outlines an approach to reducing gift officer turnover during comprehensive campaigns by investing in the human capital management (HCM) program. While many universities have begun to create HCM programs, I suggest creating a position specifically focused on the retention of gift offices to ensure that universities and non-profits can be successful in reaching ambitious campaign goals. Campaigns are an intrinsic part of university advancement but the average tenure for a gift officer nationally is $18-24$ months. This is a critical problem for universities during comprehensive campaigns because the fundraising team cannot afford to be training new staff during such ambitious campaigns. Solving turnover in the gift officer ranks requires a comprehensive program to recruit, retain and mentor gift officers so that they understand the mission of the organization and the department, understand their role in the team's success and have the tools and support necessary to achieve their professional goals.

International Journal of Educational Advancement (2010) 10, 99-107. doi:10.1057/ijea.2010.13

Keywords: retention; human capital; turnover reduction

Correspondence: Christy Thomas

College of Arts \& Sciences, University of Washington,

050 Communications Building, Box 353765, Seattle,

Washington 98195-3765, USA

E-mail: crt7@u.washington.edu
UNDERSTANDING THE ROLE OF HUMAN CAPITAL MANAGEMENT (HCM) PROGRAMS

Higher education and other non-profits attract employees because these 
talented, diverse staff members are motivated by the mission of the organization. These employees see their work as adding value to the organization, even if the employee does not receive huge financial rewards, stock options or other perks offered in the for-profit world. As the field of university advancement has grown and the need for fundraisers at all levels of organizations increases, frontline fundraisers have more professional opportunities and organizations must find ways to attract and retain the best talent.

A number of universities have created HCM programs that develop recruiting, retention and professional development practices to ensure success in new employee placement and development. Rice, Carnegie Mellon, UC Irvine and the University of Chicago are just a few of the institutions that have invested resources in this area to ensure the long-term success of advancement efforts. The overall premise is if the organization invests in its people, they are more likely to remain, produce better results and reduce the near constant turnover in the frontline fundraising positions (and across the rest of the division). Most of these investments are low-cost initiatives, such as performance-based review processes, internal educational sessions and opportunities to hear from senior leadership. However, these investments help employees feel more connected to the mission and that may be enough to keep staff from leaving when they have just begun the key work of cultivating and soliciting donors. As universities engage in long-term fundraising campaigns, donors are becoming more savvy and sophisticated.
Ensuring a long-term relationship between the gift officer and donor could lead to more success in securing second and third gifts during the cycle of a campaign. I propose the addition of a HCM position that focuses solely on the retention of fundraisers to help solve the issue of turnover and realize greater fundraising success.

\section{HCI POSITION TO SOLVE TURNOVER}

The overall purpose of the human capital investment position (HCIP) is to reduce gift officer turnover and build a fundraising team that will last through the public phase of a campaign. While there may be times when losing a gift officer is unavoidable (bad fit, moving for personal reasons, and so on), developing an HCIP will ensure that the leadership protects its investment in staff and enhances the effectiveness of the fundraising campaign. The HCIP will focus on three key areas: Communicating the Vision, Building the Team and Mentoring for Success.

Communicating the Vision will speak to the need for the leadership team to provide clear direction to the gift officers on the focus of the campaign, current priorities and how each person plays a role in the overall success. This area will also focus on developing and communicating the human resources philosophy, both from the recruitment and the retention perspectives. The Building the Team component will focus on ways to create a team environment. Some of this comes from creating team goals around the campaign, such as visit goals or mini-campaigns for specific projects. This component will also focus on creating informal 
opportunities for gift officers to get to know each other and the university through community service projects. The final component, Mentoring for Success, will address the area of midcareer counseling from others in the organization. The fundraising cycle is one where the longer someone stays with an organization, the greater their success in fundraising. It can easily take three years before a gift officer raises enough money to cover the university's investment in salary, benefits and training dollars. It's often in years four and five that a gift officer truly sees the rewards of their hard work, closing six- and sevenfigure gifts.

These three areas may not seem related but they speak to the problem of gift officer turnover by addressing three needs. For the fundraising team to be successful, the group needs to understand its purpose. The leadership team must find an effective message and find ways to generate support and buy-in from all levels of the organization. Creating a sense of team among the gift officers provides a natural support system as much of their work is done independently. Developing successful cultivation strategies is often more successful when done collaboratively, so creating informal team-building opportunities will help build trust between different members of the team. And finally, the mentoring program will encourage newer members of the team as they encounter typically road blocks and frustrations before closing larger gifts. The mentoring program will provide encouragement and leadership from someone other than the direct supervisor and create a better understanding of how the daily work leads to long-term success. These three components are crucial to retaining gift officers because they address the retention issue from a more holistic perspective, focusing on key ways to keep employees motivated. Non-profit employees are often drawn to the work because of the intrinsic fulfillment that comes from working for an organization with a higher purpose than just financial success.

\section{UNDERSTANDING THE HCI POSITION}

To implement the focus on the three key areas, I propose creating a new position as part of a Human Capital Management Team. The HCM team typically coordinates recruitment and retention services, organizational effectiveness strategies, HCM strategy, learning and professional development, new hire orientation and on-boarding and management coaching. These services are usually available to all university advancement departments. Within this group, I would create a position to serve as chief advisor on all HCM issues to the head of an Individual Giving program. This person, the Assistant Director of HCM for Individual Giving, would also implement the three components to the HCI program for Individual Giving. The position would report directly to the head of Human Capital Management and also work to support the overall goals of the HCM program. I propose creating this new position because of the volume of work Individual Giving creates for the HCM team. By having a full-time person dedicated to supporting HCM initiatives within Individual Giving, the overall effectiveness of the overall fundraising program would increase. 
This is also critical because of the relational aspect to the work of gift officers. Gift officers invest so much time in building relationships with prospective donors and this position would be the internal equivalent, focusing on building strong relationships with the fundraising staff to keep them engaged with the mission of the organization. Also, this person would focus on implementing the components for a successful HCI program, allowing the Individual Giving supervisors to devote more time to fundraising, the primary focus of their positions. While the program leadership must create and demonstrate the vision for the group, they need additional support to implement the HCI program effectively. Otherwise, these components may be lost as they focus on fundraising goals.

\section{Communicating the vision element}

To build a successful fundraising team, the Individual Giving leader must clearly articulate the vision of Individual Giving. Drawing from the overall mission of University Advancement, she/he must create a vision that affects each member of the team and shows how each person helps the organization meet the overall campaign goals. This vision should have implications for each part of the team and affect the management style and metrics for each area. Guided by the Asst. Director of HCM for IG, the leadership would develop a compelling case for why the individual giving team matters for the future of the institution. This work is similar to developing a case statement in fundraising but the case they are making is different. Instead of asking donors to invest in the university, this vision statement is about why each team member must stay invested in their work for the university. This vision should incorporate the human resources philosophy, such as the recruitment strategy and the core competencies for team members. Eventually, all components of the HR strategy, such as retention and performance management components, should incorporate the vision statement.

After going through this process, the leader needs to generate agreement from the leadership team. As part of a management meeting, the director and the new person would roll-out the vision statement to this group and then review department plans and campaign goals to ensure the vision is integrated into all levels of the organization. This is an opportunity to set the tone of the organization by creating buy-in at the management team level.

Another way to successfully develop a vision statement is to allow members of the team at all levels to offer feedback. Creating small focus groups to review the statement provides an opportunity to hear feedback from different levels of the organization. These staff members can also help with the communication of the vision, since they will have taken part in forming it.

It is not enough to simply announce the vision at a staff meeting. Part of the process should also be aligning program and gift officer metrics to the vision statement, showing the importance of the vision in each person's day-to-day work. This message should be highlighted in different meetings throughout the year 
and be seen as a guiding statement for the work of the group.

As part of the process of educating gift officers on the importance of their roles in the campaign, the Campaign Director should speak with the staff about the direction of the campaign and the overall strategy. An in-depth campaign workshop would deepen the understanding of the division's goals and each person's role in meeting them. This would also ensure that the entire team understands how the campaign priorities evolve over time.

\section{Building the team}

Building a sense of team is another way to retain gift officers because it creates a positive work environment. As the gift officer team develops during the silent phase of a campaign, there are different waves of hiring, so helping newer and older team members get to know one another is crucial for the team's overall fundraising success. To be successful, this component should include formal and informal team-building opportunities.

One way to encourage team building is by emphasizing team goals through the campaign framework. During the year, gift officers are often asked to participate with annual giving activities, such as end-of-the-calendar and fiscal-year calling periods. These annual events are opportunities to encourage gift officers to work together towards a group goal for acquisition and renewal gifts. During a campaign, there are opportunities to build excitement around projectoriented fundraising drives. These mini-campaigns provide an opportunity for different gift officers to work together with a regional focus, and target the team on specific goals for a certain time period. In total, having two to three short-term group fundraising goals a year would build group momentum during the year, in addition to meeting personal goals.

Another element of building a team would be creating community service projects twice a year. As members of a non-profit community, gift officers do not often have the chance to interact with the key recipients of donor generosity, the students and faculty of the institution. By creating community service projects in conjunction with student organizations, gift officers will meet students, work together with team members in a different way and provide service to the larger community. One idea would be to join the campus Habitat for Humanity chapter on a building project for a day. This would get the gift officers into the heart of student service and build a stronger relationship between the gift officers as they work together for a different purpose.

While mini-campaigns or community service projects may not be the best fit for every organization, these are just examples of different ways to bring the team together around a common goal. Every organization can find an activity that brings staff together around a common goal. The key is to find an activity that pulls people out of the regular office routine and provides opportunities for the group to work together and have fun.

\section{Mentoring for success}

The final element to retain gift officers is creating a mentoring program. The typical major gift officer has fundraising experience, but few possess more than four years of university 
fundraising experience. It is truly in the third through fifth year in a major gift position that the fundraiser begins to secure larger gifts. However, it is often hard to stay motivated and not be tempted to seek a new position that promises a higher salary and loftier title at another institution. The mentoring program would address the educational needs for mid-career professionals, providing valuable advice from other staff members who have successfully navigated a career in fundraising. The goals of the program are for gift officers to meet with someone further along in a career within the organization to learn more about the process of closing large gifts, discuss strategies for working with donors and the campus community, and provide encouragement about the process of developing a prospect pool.

Gift officers would become eligible to receive a mentor after 18 months with the university. The first 18 months their progress and on-boarding is handled by HCM recruiting and retention services. At 18 months, the gift officers will have completed both their six-month probationary period and one annual performance review. During this process, the supervisor and staff member will determine if having a mentor is the next step for professional development.

Mentors would be recruited from the larger fundraising staff. To become a mentor, the individual should have at least four years of experience within the organization. The mentors would preferably have closed at least one $\$ 500 \mathrm{~K}+$ gift and be identified as someone who exemplifies the core competencies. It's preferred that mentors are not supervising other gift officers.
The mentors would meet with their mentees at least once a month. At the beginning of the relationship, there would be an introduction meeting where the Assistant Director of HCM would lay out the expectations for each person in the program. This person would provide guidance to both parties to establish guidelines for this specific relationship and discuss ways the mentor and mentee might interact over the coming months. During the year, the Assistant Director would check in with both parties to ensure that the relationship is going smoothly. At the end of the year, both parties would receive a survey to provide anonymous feedback on the program.

A mentoring program serves the mentor and mentee. The mentee clearly receives important feedback on the culture of the institution, strategies for moving forward with donors and advice on career options. For the mentor, building this relationship with a newer gift officer is a way to demonstrate leadership without taking on management responsibilities. It also provides a way for the more senior employee to be part of shaping a newer employee's career path and gift success.

\section{ARGUMENTS FOR IMPLEMENTING THE HCI PROGRAM}

One of the main arguments for building the HCI program is the true cost of turnover for the gift officer positions. The cost of replacing a fundraiser is 250 percent of their annual compensation (Bliss, 2006). In addition to the financial costs, the university loses momentum in its mission to develop relationships with 
external audiences. It can take 12-18 months to build a strong enough relationship with an individual prospect to determine the proper ask amount and purpose. If the fundraising staff continues to turnover, it takes additional time to rebuild a sense of trust with the prospective donor, delaying and perhaps ending the opportunity to close a major gift (Iarrobino, 2005).

Once a campaign is underway, the development team must maintain and grow its fundraising staff to ensure momentum during the public phase of the campaign. There is still much work to be done to identify and cultivate alumni, parents and friends of the university. With a seasoned gift officer staff, the university will be able to close more gifts and use this momentum to reach its highest goals for a campaign.

The HCI program addresses three key needs for the fundraising staff. First, it provides a clear statement of the direction of the organization and helps each person understand his or her purpose within the organization. Second, it builds team among the gift officers, fostering collaboration for professionals who spend much of their time working independently. Third, it provides mentorship to gift officers during the critical part of their professional development, from 18-36 months as a gift officer. It's during this time that gift officers need the most encouragement as they work towards closing larger gifts.

While adding an additional gift officer to the team may seem to have more immediate impact on raising money, focusing on the human capital will ultimately have a larger impact on the overall fundraising totals.
Retaining gift officers helps keep the gift pipeline moving instead of stalling and starting over with a new person. An additional staff member focused on the human capital needs for individual giving and on implementing programs for the leadership team would also free up time for these leadership positions to spend more time on direct fundraising.

\section{COURSE OF DELIVERY}

The first component to implementing the program would be to create the new position within the HCM team. That will require buy-in from many layers of the organization, so it could take from six to 12 months for approval. After the position is approved, I expect it would take 3-6 months to recruit someone to fill the position. Ideally, the position could be filled by an internal candidate, someone familiar with fundraising and interested in joining the Human Capital Management office.

This person would need to spend time with the development leadership, as well as the director of the HCM program, to help create a vision statement for the Individual Giving team. Developing the vision statement is crucial to the overall success of the HCI position. After the vision statement is created, it needs to be integrated with the human resources philosophy and the group metrics for the upcoming fiscal year. The HCIP would then begin working with the leadership team to generate buy-in. Small focus groups could also be convened to provide gift officer input on the vision and the roll-out of the vision statement could take place in the third quarter of the fiscal year. This timing also gives the leadership 
team time to integrate the new vision statement into the human resources philosophy for the group and the performance metrics for the following fiscal year.

As the vision statement is underway, the Assistant Director could also begin implementing the other two components of the program: team building opportunities and the mentoring program. To encourage team building, the Assistant Director would need to collaborate with other groups on campus to find two opportunities for group community service projects with students. Once the groups and dates are identified and approved by the leadership, the Assistant Director could move forward with organizing and promoting the events. Part of the success would hinge on mixing people up so that the work teams included people who don't always work together. Evaluations would be collected anonymously after the program.

For the mentoring program, the first step would be creating goals for the relationship and clear expectations on the role of a mentor and mentee in the program. This would need to be done in consultation with the fundraising supervisors, to ensure goal agreement. Once these are established, the Assistant Director would recruit more senior gift officers as mentors and provide a training session. Then, working with the gift officer supervisors, the Assistant Director would match mentors and mentees for the initial year. For the first six months, a small group could serve as a program pilot. This will allow the Assistant Director time to evaluate the program and make changes before opening the program to the larger group of gift officers.

\section{BUDGET ANALYSIS}

The bulk of the budget would go to cover the additional salary cost of adding a staff member to the HCM team. However, this would be less than the cost of losing and replacing one gift officer a year. The program has few budgetary items, with the other large expenditures related to team-building events and staff retreats. Most institutions have some funds set aside for planning workshops/retreats, so this would simply be shifting some of those funds and adding some additional funds to support the added agenda items. Most of the office supplies and other minor budget items could be added to the overall HCM budget for each year.

\section{ASSESSMENT OF SUCCESSES AND CHALLENGES}

The first component of the HCI program would be the most difficult to measure. How does one measure the impact of having a compelling vision and providing strong leadership to an organization? In this case, I believe that investing in the creation and implementation of a strong vision statement would speak to a key motivating factor for gift officers and help connect them to the intrinsic rewards for working for the organization.

The biggest challenge would be successfully translating the vision from a statement to influence the day-to-day work of each member of the team. This requires a commitment from the vice president and then buy-in from the different levels of the leadership team. They must demonstrate the value of integrating a strong mission statement into the practical daily work. Much of this work already 
exists, but rarely are these efforts packaged under the larger idea of a vision statement.

For the second component, team building exercises are probably the easiest to coordinate because there are a lot of logistical details to the community service events. The results of the community service events will be measured through satisfaction surveys. For the fundraising component, the results from minicampaigns and annual giving priority calling will be easy to measure.

For the third component, this program may have the largest individual impact on each gift officer. The success of the program comes from clearly defining the goals and then recruiting good mentors for the staff. This area could have the largest impact if the right mentors are recruited and if they provide good career advice and perspective for the newer gift officers. Ultimately, this is not about providing another place to gossip or complain, but help newer team members understand their role and how their careers can develop as they reach certain milestones. As long as the mentoring team understands their role and how to guide the relationship, it will provide a valuable service to the gift officers and help retain gift officers in their positions for the duration of the campaign.

The overall feasibility of this program depends on the support of the vice president and the commitment to leading the Individual Giving team through the campaign. By providing a dedicated staff person to consult and implement an HCI program, the leadership will receive specifically created content with the intention of retaining gift officers. The management of the HCI program will fall in line with the overall HCM program, but offer the IG leadership team additional support to create and deliver content throughout the year.

\section{REFERENCES}

Bliss, W.G. (2006). The cost of employee turnover. The Advisor, http://www.isquare.com/turnover.cfm.

Iarrobino, J. (2005) Understanding the meaning of human capital and human capital investment in institutions of higher education. Doctoral dissertation, Boston University, Boston, MA.

Lopez-Rivera, M. (2009) Updates on billion-dollar campaigns at 32 institutions, The Chronicle of Higher Education, online publication 7 September http://chronicle.com/article/ Updates-on-Billion-Dollar/48322/. 